\title{
Encaminhamentos à mulher em situação de violência conjugal ${ }^{*}$ Referrals of women in domestic violence situations
}

\author{
Nadirlene Pereira Gomes* \\ Alacoque Lorenzini Erdmann** \\ Larissa Larie Mota*** \\ Jordana Brock Carneiro**** \\ Selma Regina de Andrade**** \\ Cintia Koerich*****
}

\section{Resumo}

As ações de enfrentamento à violência não são exclusivas do setor saúde, sendo preciso aporte de uma rede intersetorial. Trata-se de uma pesquisa baseada no método da Teoria Fundamentada nos Dados, aprovada pelo Comitê de Ética. Foram entrevistados 52 profissionais que atuam na Estratégia de Saúde da Família com o objetivo de compreender os significados atribuídos por profissionais que atuam na Estratégia Saúde da Família sobre os encaminhamentos à mulher em situação de violência conjugal. As mulheres em situação de violência conjugal são referenciadas para psicóloga e assistente social do Núcleo de Apoio à Saúde da Família. Foram mencionados como encaminhamentos externos: Centro de Referência, Delegacia da Mulher, Instituto Médico Legal e espaço hospitalar ou maternidade. No entanto, o desconhecimento acerca dos serviços e a desarticulação intersetorial comprometem o cuidado à mulher. Sugere-se o conhecimento sobre os serviços, entendimento do fluxo e articulação intersetorial.

Palavras-chave: Violência contra a Mulher. Saúde da Família. Assistência Integral à Saúde da Mulher. Psicologia. Apoio Social.

\begin{abstract}
Actions against violence are not the responsibility of the health sector alone. They require an intersectoral network support. This is a research based on the Grounded Theory method, approved by the Ethics Committee. Fifty-two professionals working in the Family Health Strategy were interviewed in order to understand the meanings attributed by these professionals concerning women in situations of domestic violence. Women in domestic violence situations are referred to a psychologist and a social worker from the Family Health Strategy Nucleus. Some centers were mentioned as external referrals: Reference Center, Women's Police Station, Institute of Forensic Medicine and hospital space or maternity. However, the lack of knowledge about the services and intersectoral disarticulation harms women's care. Knowledge about the services, understanding about the flow and intersectoral coordination are the improvements suggested.
\end{abstract}

Keywords: Violence Against Women. Family Health. Comprehensive Health Care. Psychology. Social Support.

\# O manuscrito é financiado pela FAPESB, sob o n. 6392/2011. Bol. 2366/2011, como recorte do projeto de pós-doutoramento "Gomes NP. Mulheres em situação de violência conjugal: construindo práticas de cuidado de enfermagem e saúde na ESF. Florianópolis: Universidade Federal de Santa Catarina; 2012".

* Pós-doutoranda em Enfermagem pela Universidade Federal de Santa Catarina. Doutora em Enfermagem. Bolsista FAPESB. Docente Adjunta da Escola de Enfermagem da Universidade Federal da Bahia (UFBA). Departamento de Enfermagem - UFBA. Salvador-BA, Brasil. E-mail: nadirlenegomes@hotmail.com

** Doutora em Filosofia da Enfermagem. Professora Titular do Departamento de Enfermagem da Universidade Federal de Santa Catarina (UFSC). Departamento de Enfermagem - UFSC. Florianópolis-SC, Brasil.

*** Enfermeira. Mestranda do Mestrado Profissional em Gestão do Cuidado em Enfermagem. Departamento de enfermagem - UFSC. Florianópolis-SC, Brasil.

**** Enfermeira. Pesquisadora pelo Grupo de Estudos e Pesquisa em Bioética e Cuidado Humano. Universidade de Passo Fundo - UPF. Passo Fundo-RS, Brasil.

***** Doutora em Enfermagem. Professora do Departamento de Enfermagem da UFSC. Departamento de Enfermagem - UFSC. Florianópolis-SC, Brasil.

****** Enfermeira. Mestranda em Enfermagem do Programa de Pós-Graduação em Enfermagem da UFSC. Departamento de Enfermagem - UFSC. Florianópolis-SC, Brasil.

As autoras declaram não haver conflitos de interesse. 


\section{INTRODUÇÃO}

Em 2011, o número de mulheres entre 15 e 44 anos que foram a óbito por causas associadas à violência de gênero foi maior quando comparado às mortes por doenças como câncer, AIDS, doenças respiratórias, metabólicas, infecciosas e acidentes de trânsito' .

A violência contra a mulher traz implicações para a economia do País, seja em função de sua repercussão direta na saúde da mulher agredida, gerando custos ao sistema de saúde, seja na condição de subsistência de sua família, onerando as políticas públicas pelo subsídio e apoio, ou, ainda, na produtividade econômica, pois várias delas precisam se retirar de seus empregos, quando ainda os possuem². Para os serviços de saúde, a repercussão financeira pode ser percebida pelo custeio do atendimento médico, financiamento de tratamentos curativos e de reabilitação das vítimas ${ }^{3}$.

A vivência de violência pela mulher pode estar associada a problemas digestivo e circulatório, dores e tensões musculares, lesões físicas, alterações menstruais, doenças sexualmente transmissíveis, gravidez indesejada, abortamento espontâneo, ansiedade, depressão, baixa autoestima e transtorno de estresse pós-traumático (TEPT) ${ }^{2,4,5}$.

A identificação precoce de mulheres com história de violência conjugal, ou vulneráveis a esta, é de sumária importância no sentido de reduzir os efeitos dos danos sobre sua saúde e a produtividade econômica. Considerando a abrangência e a formação de vínculo entre os profissionais e a comunidade, a Estratégia Saúde da Família (ESF) possibilita a detecção precoce e acolhimento dessa usuária, antes que ocorra um episódio mais grave de agressão ${ }^{6}$. Assim, as equipes de Saúde da Família têm como desafio o enfrentamento da violência de gênero e a construção de saberes e tecnologias preventivas, não se atendo somente às investigações após o surgimento de indicativos, como lesões físicas, por exemplo ${ }^{3,7}$.

O potencial que a atenção primária tem para traçar meios de intervir sobre essa condição advém de seu princípio de integralidade, segundo o qual o reconhecimento da violência se dá pela ótica de toda a sua complexidade, que tange desde ações promotoras da não violência, até prevenção e tratamento aos casos já identificados, que, por suas características, deve ser entendido e atendido de forma interdisciplinar e intersetorial ${ }^{8}$.
Todavia, é consenso entre os profissionais que as ações de enfrentamento à violência não são exclusividade do setor saúde, sendo preciso aporte de uma rede bem estruturada e intersetorial, composta pela polícia, justiça, assistência social e educação, entre muitos outros, com vista a garantir que as mulheres não tenham seus direitos violados $^{6}$. Nessa perspectiva, nos questionamos: Quais os significados atribuídos por profissionais que atuam na ESF sobre os encaminhamentos à mulher em situação de violência conjugal? Essa questão derivou da questão principal do estudo: Quais os significados das interações e ações experienciadas pelos profissionais sobre as práticas de cuidado de enfermagem e saúde às mulheres em situação de violência conjugal no âmbito da ESF?

O estudo teve como objetivo compreender os significados atribuídos por profissionais que atuam na ESF sobre os encaminhamentos à muIher em situação de violência conjugal.

\section{MÉTODO}

Este estudo, de natureza qualitativa, adotou o referencial metodológico da Grounded Theory ou Teoria Fundamentada nos Dados (TFD) ${ }^{9}$. Foi realizado sob os auspícios da Fundação de Amparo à Pesquisa do Estado da Bahia - FAPESB, para desenvolvimento do projeto de pós-doutoramento intitulado "Mulheres em situação de violência conjugal: construindo práticas de cuidado de enfermagem e saúde na ESF".

O local de estudo constituiu-se de um Distrito Sanitário de um município de Santa Catarina, Brasil, composto por cinco centros de saúde, nos quais atuam 16 equipes de saúde da família. Esse distrito tem o suporte matricial de um Núcleo de Apoio à Saúde da Família (NASF). O distrito sanitário foi selecionado intencionalmente devido às distintas características socioeconômicas dos contextos comunitários, com vistas a uma compreensão ampliada sobre o cuidado à mulher em situação de violência conjugal.

Participaram do estudo 52 sujeitos, dos quais 17 técnicos de enfermagem, 13 enfermeiros e 12 médicos; dois psiquiatras, dois psicólogos e uma assistente social; e cinco coordenadores de saúde, responsáveis pelos Centros de Saúde do distrito selecionado, configurando o primeiro, segundo e terceiro grupos amostrais, respectivamente. A seleção 
dos sujeitos seguiu o critério de Amostragem Teóri$\mathrm{ca}^{9}$, que permite ao pesquisador um entendimento mais profundo dos casos analisados, selecionados por sua relevância teórica e contribuição ao objeto de estudo. O projeto de pesquisa foi aprovado pelo Comitê de Ética em Pesquisa da Universidade Federal de Santa Catarina (Parecer n. 21560/2012).

Os dados foram coletados em entrevistas individuais, do tipo semiestruturadas, gravadas e transcritas com o consentimento dos pesquisados. A análise dos dados deu-se a partir de codificação aberta, axial e seletiva, a partir dos cinco conceitos estruturais: contexto, condição causal, condição interveniente, estratégias e consequências $^{9}$. Os dados foram organizados com o apoio do software NVivo 8.0 . Do desenvolvimento do projeto resultou o fenômeno "Reconhecendo a violência conjugal como problema de saúde pública e necessidade de gestão para o cuidado integral à mulher em situação de violência". A validação do modelo paradigmático da matriz teórica emergida foi realizada com profissionais de saúde no âmbito do distrito estudado e com dez pesquisadores com grande experiência em TFD.

\section{RESULTADOS}

As categorias aqui apresentadas relacionam-se ao encaminhamento à mulher em situação de violência conjugal identificada no âmbito da ESF. Com base nos pressupostos da TFD, essas categorias transitam pelo modelo paradigmático representando o contexto (Referindo sobre os encaminhamentos), as condições causais (Revelando entraves para o encaminhamento das mulheres) e as estratégias (Apontando estratégias para organização dos encaminhamentos) que definem a categoria central.

\section{Referindo sobre os encaminhamentos}

Entendendo contexto como um conjunto de acontecimentos que guiarão as estratégias de ação / interação ${ }^{10}$, as subcategorias, a seguir apresentadas, nos permitem compreender os encaminhamentos à mulher em situação de violência conjugal realizados pelos profissionais que atuam no âmbito da ESF:

Referenciando para psicólogo e assistente social do NASF

Considerando a necessidade de apoio psicológico e/ou social, a maioria das mulheres é encaminhada pelos profissionais que atuam na equipe mínima para a psicóloga e/ou a assistente social do NASF. As seguintes falas expressam tal encaminhamento interno:

Sempre quando eu pego um caso desse, eu encaminho pelo menos para o atendimento psicológico e para assistência social, para ela ir lá fazer uma visita, fazendo todo um acompanhamento familiar, ver como é que está essa pessoa, essa família, como é que está vivendo. (E-12)

Às vezes a gente aciona também a assistência social do próprio NASF, que vai trazer esses recursos necessários para dar esse suporte a ela e vai ver o que ela necessita e se precisa mudar de local, de cidade, para onde que ela pode ir, para onde vai fazer esse suporte. (Pc-1)

Alguns casos se encaminham para atendimento em grupo ou aconselhamento individual com a psicóloga. (E-10)

Encaminhamento externo só quando é casos mais grave, senão ele acaba sendo interno: tem a psicóloga aqui que atende a família, tanto a mulher quanto a criança também. (E-5)

\section{Encaminhando para o centro de referência}

Os psicólogos e assistentes sociais, ao conhecerem a história das mulheres, as encaminham para o Centro de Referência da Mulher. Seguem falas de psicóloga e assistente social referindo esse tipo de encaminhamento:

Quando a violência é crônica, temos o Centro de Referência da Mulher, que atende a mulher em situação de violência que também faz uma parceria. (Pc-2)

(...) geralmente situação de violência que chega para a gente, a gente acaba encaminhando para o Cento de Referência de Atendimento à Mulher em Situação de Violência. (AS-1)

\section{Encaminhando para o hospital e materni- dade}

Ponderando a necessidade de cuidado à saúde das mulheres, os encaminhamentos mencionados foram hospital e maternidade. Esses encaminhamentos foram dados diante de casos 
considerados graves de violência física e/ou sexual, conforme assinalam as falas dos profissionais entrevistados:

(...) no caso de violência atual, violência física ou sexual, a gente tem um esquema de encaminhamento da violência daqui do município. Encaminhar para o Hospital Universitário. (M-2)

\section{Encaminhando para o Instituto Médico Legal (IML)}

Quando a vivência de violência gera danos físicos à mulher, alguns profissionais entrevistados fazem o encaminhamento para o IML. As falas a seguir permitem visualizar essa situação:

Se ela estiver com alguma lesão, encaminho para fazer o exame de corpo e delito. (M-4)

Tem um encaminhamento vinculado ao Instituto Médico Legal com todos os exames físicos (...) porque a mulher foi espancada. (M-2)

Se precisar fazer um corpo de delito, encaminha, mas aí tem que ir antes para a delegacia, tem que fazer boletim de ocorrência. (E-11)

\section{Encaminhando para delegacia da mulher}

Diante de uma situação considerada grave, sobretudo por colocar em risco a vida da mulher, alguns profissionais referiram encaminhamento para a delegacia da mulher, conforme ilustram as seguintes falas:

Se eu vejo que a pessoa está em risco iminente, eu instruo que essa pessoa procure a delegacia da mulher. (M-7)

Se a coisa ficar séria deve procurar ajuda, denunciar, procurar a delegacia da mulher. (E-10)

(...) se for um caso mais grave, primeiro é orientar a mulher se acontecer alguma coisa procurar fazer o boletim de ocorrência. (M-9)

\section{Revelando entraves para 0 encaminha- mento das mulheres}

O estudo permitiu desvelar os entraves para os encaminhamentos à mulher em vivência de violência conjugal identificadas no âmbito da ESF, os quais representam as condições causais que influenciam o fenômeno, estando associadas à ocorrência do contexto ${ }^{10}$.

Referindo não saber para onde encaminhar

O desconhecimento acerca dos serviços de apoio à mulher em situação de violência foi apontado como um empecilho para os encaminhamentos:

Tem hora que eu não sei o que fazer. Tem horas que às vezes eu deixo paciente aqui e vou ali fora falar com o clínico ou vou consultar a psicólogo. E pergunto: "O que é que eu faço? Para quem eu vou encaminhar?" Eu não sei. (E-9)

Além da delegacia da mulher, não conheço nada específico nessa área. Também nem sei onde fica. (M-3)

(...) a questão jurídica, os encaminhamentos legais, eu realmente não saberia responder, não tenho conhecimento. (M-8)

Em algumas situações, a equipe fica até recuada, sem saber o que fazer, qual fluxo seguir, que caminho tomar. Já aconteceu algumas vezes. (...) é um pouco obscuro qual caminho tomar. (C-2)

\section{Referindo desconhecer o funcionamento do serviço}

Os profissionais desconhecem o funcionamento dos serviços, situação que contribui para o não encaminhamento:

Eu não sei nem o que é feito lá (centro de referência). Eu sei onde é, mas eu não sei como que procede lá. (M-4)

Na verdade, não sei muito como funciona a delegacia da mulher, o que eles fazem para proteção dela. (TE-2)

Referindo sobre a desarticulação dos serviços em rede

Profissionais que atuam na equipe mínima, no NASF e os coordenadores das 16 equipes de saúde entrevistadas sinalizam para a desarticulação dos serviços, o que compromete os encaminhamentos:

A gente não tem nenhuma forma de parceria que pudesse encaminhar daqui para o centro de referência. (E-3) 
(...) a gente não sabe nem o quê que acontece depois que a gente encaminha para esses serviços. (TE-10)

(...) acionar a rede não é tão fácil. A gente acaba muitas das vezes tendo uma resposta meio frustrante. E aquela pessoa acaba voltando aqui para nós. (...) o problema não deixa de ser nosso. (M-7)

A rede não sabe trabalhar muito bem ainda com violência. Acho que ela está um pouco desarticulada ainda. As coisas se perdem muito: o que é função de um, o que é função do outro, os fluxos. É bem difícil de organizar e o que acontece é que daí fica todo mundo perdido, ninguém sabe para onde mandar. (C-3)

\section{Apontando estratégias para organização dos encaminhamentos}

Consideram-se estratégias as interações ou ações realizadas, ou a serem implementadas, no sentido de responder a um fenômeno ${ }^{10}$. A fim de modificar o contexto, foram propostas as seguintes estratégias:

\section{mento \\ Buscando conhecer os serviços e funciona-}

Segundo os profissionais de saúde entrevistados, o conhecimento dos serviços e seu funcionamento viabilizam os encaminhamentos:

(...) eu acho que é preciso direcionar essa pessoa para onde ela tem que ir. Eu acho que esse é o nosso papel aqui. (...) a gente tem que estar preparado para todas as situações que aparecem para a gente, inclusive essa. (...) expor para ela que caminho ela tem que seguir (...) não deixar ela perdida no meio do caminho: dizer aonde que é, como ela faz pra chegar lá? Com quem ela tem que falar? (TE-1)

(...) é preciso que a gente saiba o que fazer, para onde focar. (...) tu saber para onde tu vai direcionar aquela pessoa. Se não, fica muito um joga para um lado, um joga para o outro. (TE-10)

(...) uma coisa que ajudaria era a gente ter uma visão de cada órgão, como cada órgão atua, que é o da violência contra o idoso, o da saúde da mulher, conselho tutelar. (E-2)

\section{Buscando entendimento do fluxo}

A compreensão do fluxo também foi apontada pelos entrevistados como estratégias que favorecem os encaminhamentos:

Temos que saber qual fluxo correto, quais os caminhos que devem ser tomados e buscar apoio na rede social que existe no bairro ou no município também. (E-2)

Eu acho que o que seria mais importante mesmo é o estabelecimento de um fluxo que seja confiável e pouco penoso, para que a gente pudesse acionar, nesse caso. (M-7)

É preciso entender o fluxo, iria melhorar muito para o paciente e para mim enquanto profissional também. Sabe uma realização? E aí eu ia dizer assim: "Eu fiz alguma coisa. Eu fiz a diferença. Para aquela pessoa, eu fiz a diferença". (E-9)

\section{Buscando articulações com os serviços}

A busca pela articulação com os demais serviços desvelou-se enquanto uma estratégia para os encaminhamentos e organização dos fluxos, deixando os profissionais mais seguros quanto ao atendimento ao usuário no serviço referenciado:

(...) é reforçar um vínculo dessas entidades com a Saúde da Família. Eu acho que o caminho é esse. É que, historicamente, tem um pessoal do Conselho Tutelar que vem aqui no posto conversar, marca reunião e vem aqui discutir o caso. Então, se a gente tivesse esse vínculo com o órgão responsável pela saúde da mulher, facilitaria bastante. (E-2)

É gratificante saber para onde encaminhar essa pessoa, e saber que vai ter uma continuidade nesse tratamento. (TE-5)

Divulgando os serviços para a comunidade Informações sobre os serviços podem ser divulgadas nos espaços da saúde como forma de orientar as mulheres quanto aos locais possíveis para buscar ajuda no processo de enfrentamento da violência conjugal:

Acho que deve ter divulgação na unidade: do que a mulher pode fazer; aonde que ela vai; o endereço; o que ela precisa fazer. (TE-6)

(...) de repente cartazes no posto de saúde (...) com locais onde ela possa procurar. (TE-4) 


\section{DISCUSSÃO}

O estudo revela que vem se delineando, no âmbito do distrito sanitário estudado, um fluxo de referenciamento da mulher em situação de violência conjugal para psicólogos e assistentes sociais do NASF, visto que a maioria dos profissionais refere acionar apoio matricial de tais profissionais. Esses, por sua vez, encaminham a mulher para o centro de referência. Vale salientar que, diante dos casos considerados graves, a equipe de referência realizou encaminhamentos externos, para os serviços de cunho jurídico-policial e de atendimento hospitalar.

A maioria dos profissionais declara que referenciam as mulheres para apoio matricial junto a psicólogos e assistentes sociais do NASF. Com o objetivo de fomentar a expansão da ESF, em 2008 o Ministério da Saúde implantou o NASF, buscando melhorar a qualidade e alcance da assistência prestada e fortalecer os vínculos necessários com os usuários ${ }^{11}$. A portaria que estabelece o NASF prevê ações de apoio matricial e tem suas forças centradas no planejamento, educação continuada, promoção da saúde e atendimento de $\operatorname{casos}^{12}$. A abordagem interdisciplinar proposta possibilita as práticas de cuidado em saúde, inclusive para o enfrentamento às questões ligadas à violência de gênero ${ }^{13}$.

Muitas mulheres permanecem por ano na relação conjugal permeada pela violência conjugal. Entre os motivos, os estudos apontam para dependência financeira e emocional, medo frente à impunidade constatada e pelo sentimento de vergonha por terem suas intimidades investigadas ${ }^{5}$. Assim, aumentam-se as chances de se cronificar, alimentando o ciclo da violência conjugal. Daí os encaminhamentos para os centros de referência que se constituem porta de entrada de acolhimento e escuta não julgadora de mulheres em situação de violência.

No espaço dos Centros de Referências, ocorre o acolhimento / atendimento por psicólogos e assistentes sociais, além de repassadas orientações de cunho jurídico. Todas essas ações visam contribuir para o fortalecimento da mulher na busca pela sua cidadania, por meio de acompanhamento permanente e monitoramento. Os centros devem funcionar como articuladores entre as demais instituições e serviços que pertençam à rede de atendimento ${ }^{13}$. Quando diante de casos considera- dos graves, envolvendo lesões físicas importantes, violência sexual ou ameaças de morte, a equipe de referência realiza encaminhamentos externos. Foram mencionados pelos entrevistados encaminhamentos para a Delegacia da Mulher, IML e serviços de saúde de alta complexidade.

No que tange aos serviços de alta complexidade mencionados pelos entrevistados, como hospital e maternidade, vale salientar que esse tipo de encaminhamento é escolhido quando a vítima apresenta quadro grave, ao contrário das unidades de saúde, que recebem casos de trauma mais brandos ${ }^{14}$. Em geral, os serviços de saúde ambulatorial e hospitalar, apontados como os mais procurados, gera o atendimento apenas das agressões físicas ${ }^{15}$. No entanto, muitas mulheres dão entrada nos serviços de pronto-atendimento por tentativa de suicídio associada à vivência de violência doméstica ${ }^{16}$.

As mulheres cujos casos foram considerados graves, conforme significados atribuídos pelos sujeitos, são encaminhadas para atendimento jurídico-policial, sendo mencionados a Delegacia da Mulher e o IML. Além de procedimentos técnicos e exames, o IML tem por objetivo, ainda, promover o acolhimento apropriado às mulheres ${ }^{17}$. Estudo realizado no setor de Odontologia do IML de Belo Horizonte com 108 vítimas de lesões corporais mostrou que $63 \%$ das mulheres vinham de delegacias de plantão noturno, final de semana e feriado, portanto não especializadas no atendimento à muIher, e que $32,3 \%$ delas representavam violência de gênero. Dos demais $37 \%$, o quantitativo de $35,2 \%$ vinha de delegacia de mulheres ${ }^{18}$. Os dados, além de sugerirem que as mulheres buscam a delegacia quando sofrem lesões físicas importantes, sinalizam para a ocorrência dessas agressões nos finais de semana ou à noite, quando seus companheiros estão em casa, e muitas delegacias especializadas no atendimento à muIher não funcionam em regime de 24 horas.

Ainda com base na percepção da gravidade do caso, os profissionais entrevistados referem encaminhamento à Delegacia da Mulher, sobretudo quando consideram risco de vida para ela. Pesquisa desenvolvida em um município do Rio Grande do Sul mostrou que, em 2009, dos 460 crimes enquadrados na Lei Maria da Penha apurados por meio de inquéritos policiais, $47 \%$ re- 
presentavam crime de ameaça, 28\% eram crimes de lesão corporal, $6 \%$ eram crimes de vias de fato e $13 \%$ eram crimes classificados como diversos, ou seja, desobediência à ordem judicial, calúnia, difamação, dano, perturbação da tranquilidade e tentativa de homicídio. Esses números não se diferem dos encontrados no ano de 2010, quando, num total de 278 caracterizados pelos mesmos critérios, $47 \%$ eram crimes de ameaça, 26\%, crimes considerados como lesão corporal, 5\%, crimes de vias de fato, $5 \%$, crimes de injúria e $17 \%$ correspondiam a crimes diversos ${ }^{1}$.

Seguindo a tendência mundial, o número de casos de violência perpetrada contra a mulher cresce vertiginosamente, assim como a quantidade de delegacias especializadas nesse tipo de caso $^{18}$. A busca por atendimento na Delegacia de Defesa das Mulheres se dá pelo anseio de justiça e punição ao agressor. No entanto, a estrutura precária, baixa resolutividade, a falta de preparo da instituição policial e jurídica vêm contribuindo para que as mulheres desistam de dar continuidade nos trâmites legais ${ }^{14}$.

A falta de resolutividade do serviço não é o único entrave para o empoderamento das mulheres. Os entrevistados apontam, ainda, para o desconhecimento por parte dos profissionais acerca dos serviços para apoio à mulher, bem como seu funcionamento e a articulação entre eles. Corroborando com nossos achados, pesquisas revelam que os profissionais da área da saúde vêm identificando situações de violência de gênero, sendo que a maior dificuldade se encontra em não saber como realizar os encaminhamentos ${ }^{3,6}$.

Os profissionais desconhecem o caminho percorrido pelas vítimas na tentativa de busca por proteção e atuam de forma isolada dos demais setores ${ }^{15,19}$. A atenção destinada às mulheres violentadas é fragmentada e pontual; os serviços não estão preparados para recebê-las e tratá-las integralmente. Por conta dessa desarticulação, as mulheres geralmente buscam vários serviços, os quais oferecem recursos pouco efetivos frente às necessidades demandadas por elas ${ }^{14}$.

Nesse contexto, o trâmite da mulher em busca de apoio para sair da relação de violência ainda é muito desgastante devido à ausência de uma rede estruturada, articulada e eficiente que a apoie e torne o percurso menos árduo ${ }^{19}$. Essa rede ainda encontra-se em construção na maioria dos municípios, mas já se sabe que qualifica o atendimento às mulheres ${ }^{15}$. Vale salientar que esse fluxo deve ser flexível e considerar as especificidades da mulher. Pesquisa sinaliza que é impossível identificar um único fluxo que seja preciso e eficiente. Pelo contrário, o caminho a ser percorrido é amplo e diverso, dependendo da realidade de cada caso. A maioria das vítimas começa a traçar sua rota pela Delegacia da Mulher, outras procuram os juizados, outras, ainda, nem sequer sabem ao certo se desejam manter a acusação contra seus agressores, retornando ao domicílio antes mesmo de efetivar a ocorrência da agressão ${ }^{19}$.

Diante desse contexto, os profissionais entrevistados compreendem ser necessária a organização da atenção primária para a realização dos encaminhamentos, o que requer conhecimento sobre os serviços, seu funcionamento, bem como entendimento do fluxo e articulação intersetorial. Parceria entre o Ministério da Saúde e organizações não governamentais tem formulado material educativo e oferecido capacitação aos profissionais de saúde, instruindo acerca dos encaminhamentos, embora muito ainda haja para se fazer ${ }^{6}$.

Em todo o mundo, a violência vem se destacando como preocupação entre as governanças. Devido ao elevado número de vítimas e à magnitude de suas consequências, a Organização Pan-Americana de Saúde a definiu como uma endemia, fato que implica o desenvolvimento de políticas específicas, por ter se tornado um problema de saúde pública ${ }^{14}$. São necessárias medidas que efetivem políticas públicas no atendimento à demanda da violência de gênero, criação de programas no formato de assistência às mulheres e que incluam os agressores e a oferta de novas possibilidades à mulher agredida ${ }^{1}$. Para isso, torna-se essencial a responsabilização compartilhada entre o serviço de saúde, das mulheres envolvidas e da sociedade em geral ${ }^{7}$.

\section{CONCLUSÃO}

O estudo mostra que, em geral, as mulheres em situação de violência conjugal são referenciadas para psicóloga e assistente social do NASF, que muitas vezes as encaminham para o centro de referência. Os casos de violência sexual e física consideradas graves recebem encaminhamentos externos, sendo mencionados: delegacia da mulher, IML e espaço hospitalar ou maternidade. 
Todavia, fica claro o despreparo dos profissionais que atuam na ESF no que tange aos encaminhamentos à mulher em situação de violência conjugal. Muitos declararam não saber para onde encaminhar as mulheres, desconhecer o funcionamento dos serviços e criticaram a não existência de uma rede para atendimento à muIher. Como estratégia para a eficiência dos enca- minhamentos, o estudo aponta para as seguintes ações: o conhecimento sobre os serviços, entendimento do fluxo e articulação intersetorial.

O estudo se limita às especificidades sociais e políticas do cenário do estudo, apontando para o desenvolvimento de pesquisas que abordem a experiência de municípios com características diferentes.

\section{REFERÊNCIAS}

1. Carneiro AA, Fraga CK. A Lei Maria da Penha e a proteção legal à mulher vítima em São Borja no Rio Grande do Sul: da violência denunciada à violência silenciada. Serv Soc. 2012;(110):369-97.

2. Gomes NP, Diniz NMF. Homens desvelando as formas da violência conjugal. Acta Paul Enferm. 2008;21(2):262-7.

3. Oliveira MT, Samico I, Ishigami ABM, Nascimento RMM. Violência intrafamiliar: a experiência dos profissionais de saúde nas Unidades de Saúde da Família de São Joaquim do Monte, Pernambuco. Rev Bras Epidemiol. 2012;15(1):166-78. 4. Carvalho-Barreto A, Bucher-Maluschke JSNF, Almeida PC, Souza E. Desenvolvimento humano e violência de gênero: uma integração bioecológica. Psicol Reflex Crit. 2009;22(1):86-92.

5. Deeke LP, Boing AF, Oliveira WF, Coelho EBS. A dinâmica da violência doméstica: uma análise a partir dos discursos da mulher agredida e de seu parceiro. Saúde Soc. 2009;18(2):248-58.

6. Borsoi TS, Brandao ER, Cavalcanti ML. Ações para o enfrentamento da violência contra a mulher em duas unidades de atenção primária à saúde no município do Rio de Janeiro. Interface. 2009;13(28):165-74.

7. Guedes RN, Fonseca RMGS. A autonomia como necessidade estruturante para o enfrentamento da violência de gênero. Rev Esc Enferm. 2011;45(Suppl 2):1731-5.

8. D'Oliveira AFPL, Schraiber LB, Hanada H, Durand J. Atenção integral à saúde de mulheres em situação de violência de gênero: uma alternativa para a atenção primária em saúde. Ciên Saúde Colet. 2009;14(4):1037-50.

9. Strauss AL, Corbin J. Pesquisa qualitativa: técnicas e procedimentos para o desenvolvimento de teoria fundamentada. Porto Alegre: Artmed; 2008.

10. Charmaz K. A construção da teoria fundamentada: guia prático para análise qualitativa. Porto Alegre: Artmed; 2009. 11. Lisboa AV, Santos AL, Bassoli FA, Paiva ND, Fernandes TC. Escuta de famílias em domicílio: ação do psicólogo na Estratégia de Saúde. Psicol Ciên Prof. 2011;31(4):748-61.

12. Ferreira Neto JL. A atuação do psicólogo no SUS: análise de alguns impasses. Psicol Ciên Prof. 2010;30(2):390-403.

13. Pougy LG. Desafios políticos em tempos de Lei Maria da Penha. Ref Katálysis. 2010;13(1):76-85.

14. Santini LN, Nakano MAS, Lettiere A. Percepção de mulheres em situação de violência sobre o suporte e apoio recebido em seu contexto social. Texto Contexto Enferm. 2010;19(3):417-24.

15. Presser AD, Meneghel SN, Hennington EA. Mulheres enfrentando as violências: a voz dos operadores sociais. Saúde Soc. 2008;17(3):126-37.

16. Correia CM. Vivência de violência doméstica em mulheres que tentaram suicídio. Salvador (BA): Universidade Federal da Bahia; 2011.

17. Drezett J, Pedroso D, Meirelles AC, Gebrim LH. A clínica em situações de abuso sexual: aspectos conceituais e atuação interdisciplinar. Mundo Saúde. 2012;36(2):346-50.

18. Rezende EJC, Araújo TM, Moraes MAS, Santana JSS, Radicchi R. Lesões buco-dentais em mulheres em situação de violência: um estudo piloto de casos periciados no IML de Belo Horizonte, MG. Rev Bras Epidemiol. 2007;10(2):202-14. 19. Meneghel SN, Bairros F, Mueller B, Monteiro D, Oliveira LP, Collaziol ME. Rotas críticas de mulheres em situação de violência: depoimentos de mulheres e operadores em Porto Alegre, Rio Grande do Sul, Brasil. Cad Saúde Pública. 2011;27(4):743-52. 